auf die Prifung des Rauhreifes und dic des Thaues. Der erstere tritt nur zu selten auf, den Thau aber kann man häufiger untersuchen. Fr enthält nach $\mathrm{Ch}$ atin gegen sechsmal mehr Jod, als der Regen. Man verfäht dabei folgendermaassen:

$\mathrm{Zu} 1$ oder 0,5 Liter des Thauwassers setzt man 1 Grm. kohlensaures Kali, man nimmt um so mehr von letzterem, je mehr der aufgesammelte Thau organische Materie enthält. Man dampft ein und glüht schwach, zieht den Rückstand mit Alkohol aus, dampft ein und erhitzt den Rückstand wieder, bis er weiss ist. Es bleibt nur ein geringer Rückstand von Jodkalium, den man in 1 Decigramm Wasser löst. Man kann nun das Jod in dieser Lösung durch alle seine Reactionen erkennen. Hat man eine hinlänglich grosse Menge Thauwasser zur Untersuchung angewandt, so kann man damit so viel Jodpalladium darstellen, dass man es wägen kann. Dieses giebt in Röhrchen erhitzt Joddämpfe. (Compt. rend. T.39. Chem.-pharm. Centrbl. 1853. No.4.)

$B$.

\title{
Ueber die Heilquellen in der Nähe von Konstantinopel.
}

In der Nähe der Stadt Isnikmid unweit Brussa existiren die Bäder von Ialova, welche bei den Bewohnern von Konstantinopel und Smyrna in grossem Rufe stehen und viel besucht werden. Die Heilquellen sind Thermen, deren Temperatur $24^{\circ} \mathrm{R}$. beträgt, und die aus einem Syenitfelsen entspringen. Das ziemlich reichlich entquellende Thermalwasser sammelt sich zuerst in einem kleinen Bassin, und von diesem wird es nach den Bade-Anstalten geleitet. Es entwickelt an den Quellen einen ganz schwachen Geruch nach Schwefelwasserstoffgas, der sich jedoch in dem Badegebäude kaum mehr wahrnehmen lässt. Das Wasser besitzt einen angenehmen, leicht säuerlichen, prickelnden Geschmack und entwickelt durch starkes Erwärmen ziemlich viel Kohlensäure, die sich in 16 Unzen auf $11 / 2$ Cubikzoll beläuft. 16 Unzen, zur Trockne verdunstet, geben nach Landerer 24 Grm. festen Rückstand, und in demselben wurden gefunden: Schwefelsaures $\mathrm{Na}$ trum 3, schwefelsaurer Kalk 1, Chlornatrium 9, Chlorcalcium 1, Chlormagnesium 2, kohlensaurer Kalk 2, organische Bestandtheile 1,500 Gran, kohlensaures Gas $\mathbf{1}_{1 / 2}^{\prime}$ Cubikzoll.

Auf der Nordseite des Golfes von Nicomadia, auf Arch. d. Pharm. CXXXII. Bds. 1. Hft. 
einem kleinen Vorgebirge, findet sich eine kleine Ortschaft, Jawshandschil, in der Nähe von Konstantinopel sehr malerisch und anmuthig gelegen, wo sich auch Heilquellen befinden.

Das Heilwasser entquillt an einer kleinen Höhle, sammelt sich in einem marmornen Bassin und dient gewöhnlich nur zur Trinkkur. Die Wirkung dieses Wassers ist gelinde abführend; 2 bis 3 Gläser davon sind hinreichend, 2 bis 3 Stühle des Tages hervorzubringen. Der Geschmack desselben ist leicht säuerlich, prickelnd, und ähnelt dem des Kissinger Rakoczy, womit das Wasser überhaupt viele Aehnlichkeit hat. Das spec. Gew. ist 1,016, und 16 Unzen geben nach Landerer 32 Gran festen Rückstand, der sich zusammengesetzt zeigt aus: Chlornatrium $18 \mathrm{Gr}$, Chlormagnesium $3 \mathrm{Gr}$., Chlorcalcium $1 \mathrm{Gr}$,, schwefelsaures Natrum 7 Gr., schwefelsaure Talkerde 1,500 Gr., Spuren von kohlensaurem Natron und kohlensaurem Eisenoxydul nebst freier Kohlensäure 2 Cubikzoll. (Buchn. n. Repert. Bd.3. H. 11.) $B$.

\section{Ueber die Auflöslichkeit des wasserhaltigen und wasser- freien schwefelsauren Kalks in reinem Wasser.}

Die Angaben über die Auflöslichkeit des schwefelsauren Kalks in reinem Wasser stimmen sehr wenig mit einander überein.

In Folge dieser Verschiedenheit, besonders was den Gyps betrifft, fand sich Wittstein veranlasst, eine nochmalige praktische Behandlung dieses Gegenstandes vorzunehmen. Einer seiner Schüler, J. Pipp, unterzog sich dieser Arbeit unter Wittstein's Leitung, die Resultate derselben sind folgende:

$\mathrm{Zu}$ den Versuchen wurde ein schönes reines Stück Marienglas genommen, dessen Zusammensetzung genau der Formel $\mathrm{CaO}+\mathrm{SO}^{3}+2 \mathrm{HO}$ entsprach und das nichts Fremdartiges enthielt. Es wurde fein gerieben, ein Theil des Pulvers als Gyps und ein anderer Theil desselben nach halbstündigem Glühen als Anhydrit bezeichnet.

Die Digestion des. Wassers mit den überschüssigen Pulvern geschah in einer Temperatur, welche zwischen +15 und $20^{\circ} \mathrm{C}$. wechselte, 14 Tage lang. Von dem Filtrate wurde, um die Löslichkeit in kochendem Wasser zu ermitteln, ein Theil in einem Glaskolben so lange 